\title{
O MAL-ESTAR CONTEMPORÂNEO NA PERSPECTIVA DE CHARLES TAYLOR
}

\author{
Isabel de Assis Ribeiro de Oliveira
}

\section{Apresentação}

Em uma sociedade complexa, recortada por múltiplos e conflitivos princípios de justiça, o individualismo, entendido nos termos em que Tocqueville (1968, p. 242) o define, aparece como importante via de preservação vital. Ao mostrar como, nos "séculos da igualdade", todos buscam em si mesmos o fundamento de suas crenças e a referência para seus sentimentos, Tocqueville enfatiza a distinção entre individualismo e egoísmo.

* Este artigo apresenta resultados parciais da pesquisa "O republicanismo na perspectiva de Charles Taylor" financiada pelo CNPq. Agradeço a A. C. S. Erp, M. L. de Oliveira e T. Salem as leituras atentas da primeira versão e as críticas daí provenientes, bem como aos pareceristas da RBCS por suas observações pertinentes.

Artigo recebido em maio/2005

Aprovado em outubro/2005
Este, afirma ele, é um vício tão antigo como o mundo, que nasce de um instinto cego, como amor apaixonado e exagerado de si mesmo, eliminando qualquer virtude e levando o homem a se preferir a tudo mais. Aquele é expressão recente de um sentimento refletido, que guia cada cidadão na direção de seus familiares e amigos, abandonando assim a vida pública na grande sociedade.

A retomada do argumento tocquevilleano, no campo da ciência política, vem produzindo resultados importantes para a formulação republicana da democracia, sendo o exame de um deles o que me proponho realizar neste artigo. A relevância desta maneira de conceber a democracia decorre não apenas das limitações próprias à versão liberal que pretende superar. O núcleo central da tradição republicana contempla uma representação da política cuja positividade pode ser apreciada, mesmo sem qualquer contraste com o pluralismo. Por esta ótica, a política recupera um lugar central na organização social, abrindo um leque de práti- 
cas e modos de pensar que prometem minimizar o mal-estar contemporâneo.

A obra de Charles Taylor destaca-se nesta recuperação do legado republicano pelo tipo de relação que estabelece entre uma concepção sociológica do sujeito e a postulação de um bem comum como referência das políticas governamentais. Tal relação já vinha sendo esboçada por Sennett, em A queda do bomem público, que pode ser considerado texto seminal da releitura de Tocqueville.

Se Sennett admite que a desqualificação da esfera pública e o conseqüente refluxo para o domínio privado é fenômeno peculiar aos Estados Unidos, sugere também que tal peculiaridade está intimamente associada a mudanças no capitalismo e na religiosidade. Nesse sentido, sua análise ganha dimensão bem mais abrangente do que aquela que em um primeiro momento lhe seria conferida. Sennett está argumentando que a proeminência das relações impessoais de mercado leva a uma privatização da sociedade burguesa, na medida em que, sentindo-se incapaz de influir nos assuntos próprios ao domínio público, o indivíduo refugia-se em sua família que, como uma fortaleza, o protege da anomia e da instabilidade. ${ }^{1}$ Por sua vez, a ênfase atribuída à "vida material", típica dessa sociedade, teria adquirido uma mística especial, como decorrência do processo de secularização, radicalizando-se a subjetivação e a concomitante instrumentalização do mundo (1986, p. 21). O domínio psíquico passa, portanto, a prevalecer sobre o domínio social, redundando em impacto perverso sobre a dinâmica política, pois são as estruturas ilegítimas de poder que se fortalecem com a suposição de que é de nossa intimidade que devemos nos ocupar.

Se seu diagnóstico está correto, cabe sublinhar o erro de interpretação para o qual nos alerta. Sustenta Sennett que o mais comum é explicar o baixo nível de participação na política, característico dessa modernidade, pela pouca disposição, por parte das pessoas, de exercer o poder. Alternativamente a essa explicação de cunho psicológico, trata-se, segundo Sennett, de compreender melhor as restrições postas pela estrutura social.

Adepto da mesma perspectiva, Taylor destaca o efeito do autocentramento na instrumentalização do mundo, isto é, uma postura em que o sujeito confere caráter utilitário a todas as associações a que pertence, de modo que nenhuma demanda externa a seu self obtém o devido reconhecimento. A escolha de um modo de vida deve efetivar-se a partir de um monólogo crucial, o indivíduo indo até o "fundo" de si mesmo, encontrando o que lhe é original, para então buscar sua própria expressão vital. Para Taylor, esse tipo de existência, característico de um antropocentrismo radical, questiona a própria atribuição de sentido para a vida, levando o sujeito simplesmente a espelhar nem mesmo a natureza, mas "isto" que está a sua volta. A resultante social não poderia ser mais empobrecedora.

Seu diagnóstico, também na mesma linha do de Sennett, ganha aqui contornos ainda mais precisos. Taylor sustenta que o narcisismo, particularmente em sociedades dominadas pela relação de mercado e pela burocracia, só pode redundar no enfraquecimento da iniciativa democrática (2000b, p. 112). Um "eu" desengajado equivale a um sujeito inteiramente desinteressado de sua posição no espaço público. Acrescentando-se a essa autopercepção o elevado custo de organizar um grupo, o mais provável é que as pessoas desistam de atuar politicamente, e as que conseguem se associar encontrem enormes desafios para mobilizar maiorias significativas em torno de programas e políticas de interesse comum.

Taylor reconhece que a disseminação da linguagem dos direitos aponta para uma saída deste tipo de impasse; mas, na medida em que apenas os direitos individuais são enfatizados, é a fragmentação dos interesses que recebe a maior força propulsiva. ${ }^{2}$ A hipótese de Tocqueville quanto aos efeitos benéficos da descentralização política sobre a prática democrática (Idem, p. 119) não lhe passa desapercebida, mas atenta para a elevada probabilidade de que as pequenas unidades sejam tuteladas pelas grandes (2000a, p. 505).

Assim, na modernidade, o indivíduo encontra sua referência no próprio self, tornando-se independente das redes de interlocução que o formam ou, pelo menos, relativizando-as. A instrumentalização do mundo e a busca de um sentido para a existência no interior de si próprio seriam então os fatores responsáveis por este mal-estar. Permeada por ideais e interdições, esta identidade, em permanente busca de sentido para sua existência, efetivaria forte conexão entre selfhood e o "bem". Definindo o 
que é bom como aquilo que cada um de nós, com nossos recursos e a nosso modo, diz que é, a tolerância, transmudada em relativismo, passa a ocupar o lugar de proeminência no espaço ético.

A esse estado de coisas, porém, Taylor acrescenta o reconhecimento da vivência de uma "ética da autenticidade", como ele a nomeia, que também permeia a maneira como nos concebemos, envolvendo forte recomendação do exercício de nossa liberdade na constituição de nosso modo de viver. E é aqui que a leitura de Taylor começa a se distanciar da de Sennett, para quem a autenticidade não é outra coisa senão o nome contemporâneo do ethos puritano destituído de qualquer referência transcendental e, portanto, com efeito puramente corrosivo sobre a tessitura social. Também da análise que Simmel faz da autenticidade diferencia-se a perspectiva de Taylor. Apoiando-me aqui no texto de Salem (1992), entendo que, pela perspectiva de Simmel, a autenticidade corresponde a uma busca de singularidade capaz de tornar cada indivíduo insubstituível na trama social. Essa busca realiza-se por um movimento interno, em que o sujeito visa a seu auto-aprimoramento, dispensando mediações externas significativas. Como a autora enfatiza, essa busca da autenticidade faz com que o sujeito "institua, em torno de si, um campo refratário e interditado ao 'outro"' (Idem, p. 66).

Para Taylor, no entanto, e aqui motivado pelo texto de Trilling (1974), a tensão ou malestar derivam precisamente do conflito que a busca da autenticidade produz sobre a representação narcísica do "eu". Taylor argumenta que a busca da auto-realização é genuína, no sentido de a pessoa acreditar que deve construir a seu modo sua vida, sob pena de desperdiçá-la (2000b, p. 17). Em vez de limitar-se, como faz Trilling, ao registro desse desejo, que se expressa no relativismo próprio ao "cada um na sua", Taylor criticará a base ética que legitima tal anseio.

Sugere que esse ideal de autenticidade, próprio à formulação moderna do conceito de identidade, o da identidade individualizada, torna particularmente complicada a conexão presumida entre identidade e reconhecimento. Pois se o indivíduo autêntico é aquele que busca em si mesmo, em sua maneira particular de ser, a sua verdade, quem deverá ou poderá reconhecê-lo como tal?
(Taylor, 1995, pp. 227ss.). Ecoa nessa idéia a leitura de Simmel feita por Salem: quem pode me assegurar que de fato estou contatando meu sentimento, atingindo meu "interior mais profundo"? Este monólogo, na perspectiva de Taylor, não tem ponto de chegada porque seu início é equivocado, isto é, parte da presunção de uma "geração interna do eu". Apontando para a desconsideração da relevância do diálogo na produção da identidade, Taylor contra-argumenta que, se a busca da autenticidade envolve criatividade, originalidade e, provavelmente, oposição a regras sociais, ela não se esgota neste movimento. A autenticidade requer, também, abertura para um horizonte de significados, socialmente posto, pelo qual tal ou qual gesto ganha a relevância que tem; e o reconhecimento da interlocução em que, mesmo na reflexão mais solitária, um ou muitos outros nos interpelam. ${ }^{3}$

Conceituada dessa forma, deve estar claro que a busca da autenticidade produz conflito na representação narcísica do "eu". Em outras palavras, o desejo de auto-realização que desconsidere as demandas postas por nossas relações com outras pessoas ou por fatores distintos de nossas aspirações necessariamente será frustrado (Taylor, 2000b, pp. 35 e 66). A maneira alternativa pela qual Taylor concebe a autenticidade apontaria para uma forma de vida mais auto-responsável (Idem, p. 74), em que outra maneira de nos representarmos pode conduzir a outro modo de relacionamento com a política, um modo que, levando em conta o poder cotidianamente por nós delegado ao Estado, o torne mais controlável e mais permeável às iniciativas da cidadania.

Para estabelecer o potencial elucidativo de seu argumento a propósito da malaise contemporânea, apresento, na seção a seguir, o núcleo de sua tese, desdobrando-o em dois tópicos. No primeiro, trato da forma pela qual Taylor efetiva sua crítica ao self desengajado ou "pontual"; o segundo concerne esta ordem normativa na qual o sujeito se inscreve. Na segunda seção apresento o esboço da teoria republicana de Taylor, dedicando atenção especial ao seu conceito de bem social ou bem comum. 


\section{$O$ argumento de Taylor}

Colocada de maneira forte, sua tese acerca do mal-estar contemporâneo é a de que "[...] uma aspiração moderna à liberdade e à individualidade conspiraram para produzir uma identidade que parece ser a negação de tudo isso" (Taylor, 2000a, p. 35). É com vistas ao estabelecimento desta tese que Taylor fará a crítica da razão desengajada e do "self pontual", um self definido pela abstração de tudo que o constitui, exceto sua autoconsciência (Idem, p. 49). ${ }^{4}$ Esse self desengajado e, como tal, livre, instrumentaliza seus desejos, inclinações, tendências, hábitos de pensamento e sentimentos, de modo a reforçar aqui, demolir ali, construindo a pessoa que quer ser. $\mathrm{E}$ é esta uma das fontes da malaise contemporânea, dada a impossibilidade prática de se atender a esse desafio, pois todas as formas de individualismo implicam não apenas a ênfase na liberdade individual, mas também um modelo de sociedade. Em outras palavras, a elaboração acerca do self envolve uma orientação quanto ao modo pelo qual as pessoas devem viver umas com as outras. Se o individualismo está na raiz do mal-estar contemporâneo, não se trata de um individualismo que necessariamente expresse um egoísmo. Não há dúvida de que a autonomia, a exploração de si mesmo (em particular, dos próprios sentimentos) e a entrega total para o que se considera ser a boa vida caracterizam esse indivíduo. $\mathrm{O}$ individualismo, entretanto, contempla também uma representação muito particular do mundo.

Tal representação expressa-se pela linguagem do direito: as instituições relevantes da vida contemporânea, como o mercado, o Estado, as burocracias, estão todas marcadas pela idéia de sua regulação voltada para preservar e proteger os interesses individuais, pautados pela idéia de "dignidade intrínseca de todo ser humano". Estruturado desse modo, estaríamos inseridos em um contexto caracterizado pelo excesso de privacidade ou intimidade, 5 que afeta fortemente o espaço público, inibindo a criatividade pessoal, assim restrita por essas regras particularistas que organizam sua existência. A comunidade política, por sua vez, reduzida ao racionalismo da lei, ganha um dinamismo complicado, dado que o sentido de dever e lealdade para com ela, algo próprio ao conceito de cida- dania, torna-se inteiramente marginal, viabilizando o crescente domínio do aparato racional-burocrático (Idem, pp. 502 e 508; 2000b, p. 43).

A estrutura dessa construção política estaria, entretanto, fundada em uma premissa equivocada. É o ato de escolher que está sendo valorizado, algo que torna todas as opções igualmente válidas, porque livremente feitas (2000b, p. 37). A idéia de que existe um contexto significativo que estabelece que determinadas escolhas são importantes, valiosas, e outras, não, desvanece. No entanto, para que se possa sustentar a afirmação "minha vida é valiosa porque é fruto da minha escolha", é necessário aceitar a existência de algo a coragem de escolher, pelo menos - cujo valor independe de minha vontade (Idem, p. 39). ${ }^{6}$ Esse é o argumento de Taylor que me interessa comentar, destacando as passagens mais importantes.?

\section{O sujeito em pauta}

Diante da morte do sujeito pontual, ou desengajado, proclamada pelo pensamento pósmoderno, Taylor reage construindo a imagem de um self que só se constitui pelo diálogo, mesmo conflituoso, com as identidades que o outro reconhece (Idem, p. 33). A resposta para a questão "Quem sou eu?" só pode ser encontrada se definido o lugar de onde falo, na rede familiar, no espaço social, na "geografia dos status e funções sociais", na minha relação íntima com aqueles que amo e, sobretudo, "no espaço de orientação moral e espiritual dentro do qual minhas relações definidoras mais relevantes estão sendo vividas" (2000a, p. 35). Em poucas palavras, um self só existe numa rede de interlocução, por referência a uma comunidade (Idem, p. 36), definindo-se a identidade de cada um pelo horizonte em face do qual se posiciona. ${ }^{8} \mathrm{E}$ como esta identidade vai se transformando ao longo da vida, sua integridade depende do modo como vai sendo narrada.

Em After virtue, MacIntyre (1984, pp. 205ss.) trata deste tópico de forma muito cuidadosa. Se somos contadores de histórias, sustenta ele, não as criamos a partir do nada; elas são parte de um relato que nos antecede. Entramos na sociedade com um personagem já preparado, cujos papéis teremos que aprender a desempenhar para com- 
preender o que os outros esperam de nós. Essa socialização não está transmitindo apenas normas sociais, mas definindo também quem devemos ser. Tal perspectiva contrasta fortemente com o esforço feito por Locke para dar conta da identidade pessoal apenas pelo exame de situações ou eventos psicológicos. Pois o que um conceito de selfhood, enquanto narrativa, requer é, de um lado, a admissão de que eu sou o sujeito de minha história e de que esta história tem um significado peculiar; e, de outro, o reconhecimento de que sou um sujeito da história dos outros. Ser o sujeito da própria história equivale a responder pelas ações e experiências que compõem essa vida narrável. A identidade pessoal pressupõe, portanto, a unidade do caráter que a narrativa requer. Sem isso, não há história para contar. Por outro lado, se sou parte da história dos que comigo vivem, minha narrativa tem uma co-autoria. É isso que me leva a perguntar ao outro por que agiu desta ou daquela forma, pois que sou parte dessa história que o outro fez. A narrativa individual é, portanto, parte de um conjunto de narrativas interconectadas. Assim, qualquer tentativa de elucidar a noção de identidade pessoal independente e isoladamente das noções de narrativa, inteligibilidade e accountability, está destinada ao fracasso.?

Tal como MacIntyre, Taylor está introduzindo dois aspectos inexistentes na concepção liberal do sujeito: o da interlocução, pelo qual ele se constitui, e a referência a uma ordem normativa. A construção dialógica do self não apresenta maior novidade, mas a postulação da ordem normativa traz consigo questões complexas. A primeira delas concerne ao status a ser conferido ao campo valorativo: vivemos referenciados a uma normatividade objetiva ou, alternativamente, nosso diálogo revela a troca e o eventual acordo entre nossas subjetividades? Se aceita a plausibilidade da primeira hipótese, uma segunda questão se impõe, referida ao teor de verdade a ser atribuído a estas normas que constrangem o exercício de nossa vontade. Finalmente, vem à tona a questão do grau de liberdade conferido ao sujeito num contexto normativo objetivamente estruturado. A maneira como Taylor apresenta essa ordem normativa pode ser considerada um guia confiável para trilhar esse "campo minado" de nosso saber.

\section{Ordem normativa}

A crítica a qualquer pretensão de objetividade valorativa fundada em uma perspectiva sociobiológica seria, do ponto de vista de Taylor, improcedente, pois o argumento de que é impossível uma discussão objetiva sobre valores, por constituírem eles apenas uma projeção subjetiva sobre o real, estaria respaldado, paradoxalmente, na crença inquestionável na objetividade científica, que estabeleceria a validade dessa leitura do ser humano. Admitida a incongruência dessa postulação, Taylor desenvolve a idéia de que a objetividade não é atributo exclusivo do universo "não-humano". Assim, o bem ou o direito não estão, em princípio, destituídos de objetividade ou realidade (2000a, p. 56)

Para fundamentar sua hipótese, Taylor lembra que todos nós não apenas vivemos orientados por algo cujo valor reconhecemos, independentemente de nós mesmos, como buscamos hierarquizar os diversos bens que prezamos, ou seja, conferimos consistência a esses valores, o que nos permite compará-los e priorizá-los. Se a tensão e o conflito são intrínsecos a essa busca, nem por isso o precário resultado a que se chega deve ser ignorado, pois se o estabelecimento de nossa própria identidade tem caráter dialógico, torna-se importante reconhecer como pertinentes as modalidades de consenso valorativo. Tais modalidades, que organizam nosso modo de dizer o que é certo ou errado, não estão isentas das contaminações do poder, como assinala o conceito de "regimes de verdade" proposto por Foucault. Mas Taylor argumenta que o fato de nossas crenças serem em parte produto de conflitos pelo poder não necessariamente lhes retira sua racionalidade, que é o que lhes confere validade ou "valor de verdade" (1995, pp. 16ss.). Taylor sugere que se inscreva aí a possibilidade efetiva de um saber, justificando assim sua demanda por uma articulação racional acerca de nossos valores.

É este argumento que lhe permite sustentar o caráter ilusório da tese de que a articulação de um argumento ético não é nada mais do que a tentativa de imposição de uma verdade ao caos, ou de projeção de valores, de forma totalmente arbitrária, em um mundo neutro, constituído de "fatos". Admitida a impossibilidade, para o ser 
humano, de evitar o posicionamento ético (2000a, p. 99), cabe argumentar quanto ao valor deste ou daquele bem.

Uma leitura elucidativa da proposição tayloriana acima exposta é feita por Descombes (1994), que inicia seu comentário questionando a presunção de que o pensamento só pode ocorrer em uma pessoa. Certamente, Descombes não advoga a existência de um "coletivo pensante", a própria sociedade ou um "super indivíduo", como seria típico da reação de senso comum a qualquer esforço de crítica à localização do pensamento no "interior" de nós mesmos. Esse autor reconhece a dificuldade de superar tal percepção, chamando nossa atenção para pensadores clássicos que, ao substituir o indivíduo por outro sujeito, não deixaram de usar o termo "consciência", tão fortemente conectado à subjetividade. ${ }^{10} \mathrm{O}$ que deve ser retido dessa nova formulação é a existência de modos de pensar e de agir que se impõem a cada um de nós, conferindo significado à vida individual. Essas formas coletivas de existência e de ação podem ser apreendidas como conjunto de regras e usos estabelecidos, que transcendem o livre-arbítrio dos indivíduos e as convenções que entre si estabelecem. Esse conjunto - a ordem normativa - pode, portanto, ser visto como precedendo a "vontade" e a "razão" do indivíduo, o que não quer dizer que a eles seja impérvio. Descombes identifica neste legado iluminista (de atribuir o pensamento a uma mente individual) a principal dificuldade em apreender o processo pelo qual o referencial normativo externo às subjetividades se constitui. Vencida essa dificuldade, o autor pode sustentar que as instituições pensam. ${ }^{11}$

Como Taylor, tomando a sociedade como matriz para os indivíduos, antes que como instrumento a seu dispor (2000a, p. 196), Descombes dirá que, de uma perspectiva atomista radical, esse ou qualquer outro tipo de reconhecimento de um "ser social" é visto como um rebaixamento do indivíduo, de sua estatura moral, pois questiona sua liberdade de consciência e sua competência de julgar. Mas, argumenta Descombes, em relação a quem, se não a outro indivíduo, tal rebaixamento estaria ocorrendo? Trata-se, a seu ver, de reconhecer estados mentais partilháveis, ou uma regra a seguir, como condição do exercício da atividade inteligente. A linguagem, mas também as religiões, as ideologias e outras formações sociais expressariam essas formas de vida, dentro das quais fazemos aquilo que nos parece próprio.

O maior desafio no desenvolvimento desse modo de apreender a realidade é o de estabelecer o estatuto ontológico dessas regras e convenções. Descombes sugere que sejam vistas não apenas como objetos materiais ou atos mentais, mas como instituições. Assim posta, a construção de significados processa-se em um contexto institucionalizado, que estabelece a gramática (e o referencial simbólico comum) imprescindível à comunicação requerida para nossa existência. A referência a Lévi-Strauss, feita por Descombes, especifica a natureza destas regras, que são racionais sem ser racionalmente concebidas e que podem estar expressas numa fórmula arbitrária, sem que isso implique a inexistência de significado (1994, p. 114).

A escolha deste ou daquele modo de viver, que efetivamente fazemos, se dá, portanto, dentro de uma sociedade institucionalizada, que delimita nossos graus de liberdade. Daí a promessa e o desafio do republicanismo, como representação distinta da democracia, tal como posta pelo pensamento liberal.

\section{A democracia republicana}

A maneira pela qual Taylor concebe o self tem implicações diretas para a institucionalidade democrática. Por ela, o objetivo de preservar a autonomia individual requer bem mais do que a operação do sistema político liberal. Centrado em procedimentos voltados para processar a expressão dos interesses individuais, a democracia liberal afina-se pelo conceito de self pontual e reconhece apenas a noção de bem convergente. A defesa do procedimentalismo funda-se em seu potencial de proteção da liberdade de cada cidadão viver a seu modo, de acordo com sua própria definição de bem.

Mas, sustenta Taylor, essa ordem política, expressamente fundada na noção de direito, como em Rawls, implicitamente se sustenta numa concepção de bem comum endossada por todos. De resto, privilegiar o direito como instrumento de administração dos bens públicos significa mais 
do que reconhecer seu caráter formal, este que preserva o princípio de universalidade como norteador do exercício do poder. Se a linguagem dos direitos individuais presta-se para regular as demandas ao Estado, sua operação adequada requer uma "virtude cívica", entendida por Taylor como um ethos marcado pela lealdade para com a comunidade política. Não se trata, portanto, de representar o Estado como instância administradora dos bens individuais, com vistas a um interesse tão geral quanto possível, e sim de representá-lo como imprescindível à manutenção dessa sociedade. Privilegiar o direito implica, portanto, a valorização dessa racionalidade e da identidade coletiva que por seu intermédio se preserva e se reconstitui.

Por esta ótica, a maneira como se vivencia a política antecede ou estabelece a identidade individual, provendo a matriz na qual nos tornamos os seres humanos que somos. Ao mesmo tempo, tal perspectiva permite vislumbrar uma forma de vida coletiva ancorada na escolha responsável dos membros da coletividade. Mas não apenas. $\mathrm{Na}$ construção republicana da ordem democrática, a liberdade ganha margem maior para seu exercício, constituindo-se uma sociedade onde formas mais ou menos aprimoradas de vida competem entre si. Uma ética da autenticidade não prescinde da liberdade individual, no sentido de que o modo de vida que escolho é um modo meu de viver. Porém, o referencial dessa escolha está posto por algo fora de mim, que independe de meu desejo. Taylor chama nossa atenção para o efeito catastrófico da confusão desses dois modos de auto-referência, pois não há a menor possibilidade de regredirmos para uma cultura em que a primeira modalidade perca sua centralidade; mantida essa auto-referência, se desqualificarmos o que comparece fora de nós, estaremos condenados à pior forma de subjetivismo. Trata-se, pois, de compreender isso que nos une.

A esperança de aliviar o mal-estar contemporâneo está ancorada tanto na crítica à concepção liberal do sujeito como no reconhecimento de um bem que nos é comum, valioso por expressar sentimentos ou ações partilhadas. De uso corriqueiro, típico do vocabulário (católico) de exortação à superação do egoísmo, o conceito, tal como formulado por Taylor, merece atenção, requeren- do seu entendimento um afastamento desta linguagem ordinária em que o termo costuma ser empregado.

Existe um bem social irredutível? É com essa pergunta que Taylor inicia, no capítulo 7 de Argumentos filosóficos, sua reflexão acerca desse bem, admitindo, logo de partida, que tanto no pensamento acadêmico como no senso comum as opiniões se dividem e o tema é tratado de forma confusa. ${ }^{12}$

A especificação do significado do termo, tal como postulada por Taylor, visa a distinguir bem social de bem público ou convergente. ${ }^{13}$ Este último tem um referente claro (1995, p. 129) mesmo que apenas na linguagem acadêmica. Trata-se aqui do bem estatal (ou coletivamente produzido) que não pode ser usufruído por um indivíduo sem beneficiar muitos ou mesmo todos. Melhor dizendo, é público aquele bem que não sabemos ex ante a quem beneficiará. Mas tais bens são considerados bens porque correspondem às preferências individuais.

É sobre este último aspecto da definição de bem público que incide a especificação proposta por Taylor, pois se para ele é inegável que são os indivíduos que pensam, preferem e agem, todas essas manifestações expressam, para além da subjetividade individual, um contexto significativo a ela irredutível..$^{14}$ Visível em instituições, papéis, regras, leis e costumes, a dimensão especificamente pública é, portanto, distinta do conjunto de preferências dos indivíduos que circulam nesse espaço.

Para sustentar tal distinção, Taylor destacará o processo envolvido no pensamento, buscando mostrar como a linguagem em que o pensar se faz impõe restrições ao que pode ser pensado. Se a linguagem está organizada por uma gramática, que valida ou não qualquer proposição, contemplando um conjunto limitado de vocábulos, nem por isso elimina-se a possibilidade da transgressão. $O$ indivíduo pode dizer algo nunca antes dito, conferir novo significado a um termo corrente ou tornar mais flexível determinada regra gramatical. De resto, é pela violação do costumeiro que a linguagem se renova. Desta pequena viagem aos textos de Humboldt, Saussure e Wittgenstein, Taylor retira o que lhe parece essencial: o fato de que na perspectiva utilitarista, que constrói o bem público como bem convergente 
(e, portanto, redutível às preferências individuais), o contexto lingüístico está sendo desconsiderado. Tal contexto não pode ser decomposto ou desagregado, pois uma língua não é somatório de elementos e sim expressão articulada de uma cultura. É este reconhecimento que permite Taylor argumentar que um bem não pode ser assim considerado se o significado a ele atribuído não existir em uma determinada cultura.

No entanto, Taylor faz uma conexão entre língua e cultura que não está alicerçada no raciocínio que a precede. E é aqui que sua conceituação se torna problemática, pois se demonstra o caráter irredutível do domínio público (ou social), o mesmo não pode ser afirmado quanto à sua postulação de bem. Vejamos isso mais detidamente.

A mediação entre seu conceito de social ou público e sua noção de bem faz-se explicitamente. Afirma Taylor:

Nos últimos parágrafos, falei sobre a linguagem. Mas a discussão começou pelo exame de aspectos cruciais da vida social, como papéis, leis [...]. Acabamos chegando à linguagem porque tais aspectos estão claramente conectados ao fato de termos determinados pensamentos, e nossos pensamentos estarem condicionados por nossa linguagem. Mas deve estar claro, agora, que, em virtude dessas conexões, esses aspectos partilham a natureza bidimensional descrita em termos saussureanos. Estou no momento desempenhando um determinado papel, como o de pai ou professor. [...] Só posso desempenhar esse papel porque existem condições de validade definidas no conjunto de práticas e instituições que modelam a vida de minha sociedade. A maneira como eu e outros desempenhamos estes papéis, ou não chegamos a conseguir desempenhá-los, pode trazer mudanças no conjunto de condições (de validade) [...]; assim, finalmente, as práticas e as instituições só estão sendo mantidas na forma particular em que se apresentam devido aos intercursos que vão sendo efetivados em nossa vida social. Cada papel individualmente desempenhado é um ato de fala que pressupõe uma linguagem de fundo; e isso, por sua vez, é mantido por meio de atos constantemente renovados (1995, p. 135, trad. livre).

A seguir, Taylor substitui a linguagem pela cultura, argumentando que, se

[...] nos referimos ao pano de fundo de nossas práticas, instituições e entendimentos, que forma $\mathrm{O}$ análogo da língua para nossa ação em determinada sociedade, como nossa "cultura" [...], então deve estar claro que a cultura pode ser o locus dos bens. [...]. Como indivíduos, valorizamos determinadas coisas; consideramos certas realizações boas, algumas experiências, satisfatórias, e alguns resultados, positivos. Mas essas coisas só podem ser boas de um certo modo, satisfatórias ou positivas em sua maneira particular, dado o entendimento de fundo desenvolvido em nossa cultura. [...]. Se tais coisas são bens, [...] assim também é a cultura que as torna possíveis. [...]. Conseqüentemente, é difícil negar-lhe [...] [sua identidade de] [...] bem intrínseco (Idem, pp. 136-137, trad. livre).

Aqui está uma questão intrigante pois, tal como construído, o argumento implica a existência de um locus externo a qualquer cultura, fora, portanto, de um domínio contingente, de onde se possa afirmar que a cultura, por conter bens, é, ela mesma, um bem. O termo "bem" está sendo usado com dois significados distintos, sem que a distinção seja respeitada na ilação feita. O bem que nos satisfaz ou que avaliamos positivamente é, de fato, um bem, ou seja, algo que consideramos bom ter, que antepomos aos males da existência. Já a cultura escapa a este tipo de avaliação, pois não existe um locus externo a ela e simultaneamente dotado de significado no qual tal qualificação possa se alicerçar.

Suspeito que o que move Taylor nessa direção, que me parece um equívoco, é o anseio de positivar um bem intrínseco em face da dominância do relativismo ético. A meu ver, é possível contestar esse relativismo sem regredir para uma posição fundamentalista, sempre arbitrária. ${ }^{15}$ De fato, Taylor sustenta que do deísmo se passou rapidamente para uma perspectiva normativa em que Deus deixa de ser referência relevante. As fontes morais são agora a razão do mundo, apreendida por um "eu" desengajado, e/ou a competência subjetiva de discernir o justo do injusto. Ao comentá-las, Taylor argumentará que são fontes "inerentemente problemáticas" por poderem ser contestadas de um modo que a moral derivada da aceitação da existência de Deus jamais o será.

A resolução distinta chega-se fazendo outro tipo de contestação à tese relativista. O relativismo ético baseia-se na proposição de que o julga- 
mento de valor é sempre relativo ao contexto de seu enunciado; sendo assim, sistemas éticos alternativos são incomensuráveis conceitualmente e, no limite, o relativismo ético implica a inviabilidade de qualquer julgamento de valor envolvendo culturas distintas. No entanto, julgamos e chegamos a acordos acerca do que é certo e do que é errado quando nos confrontamos com práticas provenientes de contextos distintos do nosso. Como é possível isso?

O erro está em supor que sejamos capazes de reconhecer uma alteridade radical. Por via da antropologia, Gellner mostra que essa suposição é equivocada, visto que jamais um antropólogo voltou do campo de mãos vazias, ou seja, algo ele entendeu, captou, recolheu e trouxe consigo. Pela via da análise lógica, Davidson argumenta que só reconhecemos a alteridade quando identificamos a comensurabilidade. Esse autor sustenta que o argumento relativista implica dualismo insustentável (ou seja, totalmente instável) entre o esquema conceitual (que organiza) e o conteúdo organizado por esse esquema, já que um esquema conceitual alternativo não seria reconhecível por nós e, portanto, não teria como se apresentar na qualidade de esquema alternativo. Seria necessário um exílio cósmico para identificar tal alteridade, o que transformaria o observador em um extraterrestre ininteligível. Assim, quando há identificação de diferença é porque já há também alguma comensurabilidade, isto é, algum espaço de inteligibilidade mútua (Oliveira, 1998).

A aceitação dessa crítica ao relativismo permite reconhecer que quando constatamos oposições a nossos valores, estamos partilhando uma linguagem, que pode quase não ter regras, ou seja, que pode produzir uma série de equívocos e de confusões, mas que, mesmo quando precária, permite nossa comunicação. Retomando então a questão em pauta, o bem é comum aos membros de uma comunidade política, por partilharem uma mesma forma de vida. Mas não precisa ser tomado como um bem fixo, e sim como ponto de equilíbrio, que varia com os argumentos que sobre ele incidem. O bem comum, então, não é um bem intrínseco a uma cultura, mas ponto de equilíbrio entre versões distintas dela, postas em um contexto no qual está em aberto o resultado a que se vai chegar, via interlocução. Nessa visada, se a especificação do que seja o bem comum não o toma como universal, ela contém um princípio claro de universalização.

Apresentado, ainda que de forma sucinta, seu argumento, cabe então responder às questões levantadas anteriormente. Quanto à primeira - se existe uma objetividade da ordem normativa -, creio que a resposta é afirmativa, lembrando que objetividade não deve ser confundida com "essência", e sim considerada característica da irredutibilidade do bem comum ou social. O teor de verdade está referido à cultura, algo que transcende a racionalidade pura, sem que com isso perca um referencial de validade conferido pela gramática que organiza essa linguagem particular. Finalmente, com recurso às postulações de Humboldt, Saussure e Wittgenstein, deve estar clara a existência de graus de liberdade para novas falas e articulações, cujo uso confere dinamismo à linguagem e à própria cultura.

\section{Conclusão}

Na perspectiva de Taylor, a malaise contemporânea decorre de uma representação equivocada de nós mesmos, à qual se soma a anomia resultante do relativismo ético. O republicanismo aliviaria esse desconforto, na medida em que, disseminando-se outra forma de auto-representação, seríamos levados a nos envolver com o exercício do poder público, de modo a buscar realizar aquela forma de vida que nos pareça a melhor possivel.

Não há dúvida de que as exigências postas pela perspectiva republicana ao ordenamento democrático, como argumenta convincentemente Pocock (1975), não são poucas nem de fácil cumprimento. Muita atenção aos processos de socialização, particularmente à educação formal, precisa ser dada para que, já desde sua entrada no domínio público, o cidadão compreenda que herda uma sociedade organizada para a qual não contribuiu e que a ela deve lealdade pelo benefício que sua existência the confere. Ou, alternativamente, uma sociedade caótica ou injustamente ordenada, que pode ser modificada pela ação política. Admitindo-se a definição que Tocqueville nos dá do individualismo, como sentimento refle- 
tido, outra resultante da reflexão pode efetivar-se, uma vez que se altere a representação da relação entre indivíduo e sociedade.

Se esta exigência está longe de esgotar o elenco de requisitos para o funcionamento adequado de uma ordem republicana, basta mencioná-la para reconhecermos que a boa vida não está ao alcance de qualquer sociedade. Um lastro de cultura cívica, cuja existência não raro demanda um longo tempo de prática política, compõe o núcleo dessa forma de vida. E mesmo com ela, nunca se pode prever o movimento produzido pela fortuna.

Ainda assim, não parece razoável descartar este desenho da ordem política, tendo em vista não apenas sua promessa de aliviar a malaise contemporânea, como também a de propiciar um saudável e dinâmico convívio no espaço público, onde, para o bem ou para o mal, inevitavelmente nos encontramos.

\section{BIBLIOGRAFIA}

DESCOMBES, V. (1994), "Is there an objective spirit?" in J. Tully (ed.), Philosophy in an age of pluralism: the philosophy of Charles Taylor in question, Cambridge, Cambridge University Press.

FOWLER, R. B. (1991), The dance with community: the contemporary debate in American political thought. Kansas, University Press of Kansas.

JAMES, S. (1994), "Internal and external in the work of Descartes", in J. Tully (ed.), Philosophy in an age of pluralism: the philosophy of Charles Taylor in question, Cambridge, Cambridge University Press.

KITCHEN, G. (1999), "Charles Taylor: the malaise of modernity and the moral sources of the self". Philosophy and Social Criticism, 25 (3): 29-55.

MAcINTYRE, A. (1984), After virtue. Notre Dame, Indiana, University of Notre Dame Press.

MELO, M. A. (2002), "Republicanismo, liberalismo e racionalidade". Lua Nova, 55-56, São
Paulo.

MULHALL, S. \& SWIFT, A. (1992), Liberals and communitarians. Cambridge, Blackwell.

OLIVEIRA, I. A. R. (1998), "A institucionalidade democrática em contextos neo-patrimoniais", in G. Villas Boas (coord.), Territórios da lingua portuguesa, Rio de Janeiro, Editora da UFRJ.

(2002), "Human rights in Latin America", in P. Hillman e E. Cardozo, (eds.), Democracy and human rights in Latin America, Westport, Praeger.

. (2005), "Notas sobre dois livros de MacIntyre”. Lua Nova, 64: 117-128.

PETIT, P. (1999), Republicanism: a theory of freedom and government. Oxford, Oxford University Press.

POCOCK, J. G. (1975), The machiavellian moment. Princeton, Princeton University Press.

RENAUlT, A. (1989), L'ère de l'individu. Paris, Gallimard.

SALEM, T. (1992), "A 'despossessão subjetiva': dos paradoxos do individualismo". Revista Brasileira de Ciências Sociais, 7: 62-77, fev.

SENNETT, R. (1986), A queda do homem público. Rio de Janeiro, Zahar.

SKINNER, Q. (1994), "Modernity and disenchantment: some historical reflections", in J. Tully (ed.), Philosophy in an age of pluralism: the philosophy of Charles Taylor in question, Cambridge, Cambridge University Press.

SOUZA, J. (2000a), A modernização seletiva: uma interpretação do dilema brasileiro. Brasília, Editora da UnB.

. (2000b), "Uma teoria crítica do reconhecimento". Lua Nova, 50: 133-158.

TAYLOR, C. (1988), "The hermeneutics of conflict", in J. Tully (ed.), Meaning \& context: Quentin Skinner and his critics, Princeton, Princeton University Press. 
(1995). Philosophical arguments. Cambridge, Harvard University Press.

(2000a), Sources of the self. Cambridge, Harvard University Press.

(2000b), The ethics of authenticity. Cambridge, Harvard University Press.

TRILLING, L. (1974), Sincerity and authenticity. Nova York, Harcourt Brace Jovanovich.

TOCQUEVILLE, A. (1968), De la démocratie en Amérique. Paris, Gallimard.

\section{Notas}

1 Para análise das transformações efetivadas no interior desse tipo de família, cf. Sennett (1986, pp. 11 e 177-183), e, para sua conceituação do narcisismo, pp. 220,324 ss.

2 Sobre a prevalência dos direitos individuais e suas conseqüências no uso dessa linguagem, cf. Oliveira (2002).

3 A relação entre autenticidade e expressivismo é muito bem desenvolvida por Souza (2000b, pp. 146-148), envolvendo, entretanto, outra leitura de Sennett que, por razões de economia, não será comentada aqui.

4 Taylor não trabalha com o conceito de indivíduo de Dumont, mas creio que o referente do "self pontual”, explicitamente lockeano, equivale ao de "sujeito moral".

5 Para outro tipo de interpretação dos efeitos desagregadores da busca de intimidade, cf. Sennett (1986, pp. 260ss).

6 Esse raciocínio de Taylor (também exposto em 1995, p. 17) guarda enorme proximidade com aquele desenvolvido por Renault (1989) para trabalhar o conceito de autonomia do sujeito. Para Renault, só faz sentido falar em independência do indivíduo por referência à sua autonomia. Assim, para que a faculdade de escolha, independentemente do modo como quer viver, possa aparecer para o indivíduo como o cume de sua liberdade, é necessário que ele já tenha reconhecido que só se submete à lei, ou seja, àquela ordenação que não apenas tem caráter universal, como também é instituída pela própria coletividade (1989, p. 55).
7 Para outras sínteses do argumento de Taylor, cf. Fowler (1991); Mulhall e Swift (1992); Skinner (1994); Kitchen (1999); Souza (2000a); e Melo (2002).

8 A uma conclusão muito similar chega Salem, ao sustentar que "o acesso à sua esfera mais cara, supostamente mais secreta e preservada - seu inner-self - ao invés de isolá-lo do outro, pressupõe [...] a alteridade como condição imprescindível para consumar sua auto-inteligibilidade" (Salem, 1992, p. 71).

9 Para uma síntese do argumento de MacIntyre, cf. Oliveira (2005).

10 Trata-se, aqui, da consciência de classe, de Marx, e da consciência coletiva, de Durkheim.

11 “[...] o significado não está trancado no interior do indivíduo; as formas públicas e coletivas de existência e ação são seus elementos naturais" (Descombes, 1994, p. 100).

12 Nesse capítulo, Taylor usa a expressão "bem social", mas ao longo de sua obra, "bem social" e "bem comum" são tratados como sinônimos.

13 Para outra maneira de fazer essa distinção, no campo do pensamento republicano, cf. Petit (1999, pp. 121 e 259).

14 Neste ponto, o legado aristotélico e maquiavélico, tal como recuperado por Pocock (1975, pp. 74-76 e 200ss.) está sendo retomado à risca.

15 Esse ponto é tratado por James (1994, p. 7). A posição fundamentalista de Taylor pode ser percebida também em The ethics of autenticity (pp. 40-41 e 50-52). 


\section{O MAL-ESTAR CONTEMPORÂ- NEO NA PERSPECTIVA DE CHARLES TAYLOR}

Isabel de Assis Ribeiro de Oliveira

Palavras-Chave: Republicanismo; Charles Taylor; Self; Ordem normativa; Bem comum.

Este artigo apresenta o argumento de Taylor acerca do mal-estar contemporâneo, cujo foco incide na crítica ao self pontual e à sociedade política daí decorrente. A postulação de uma identidade pessoal apenas possível pela interlocução referida a uma ordem normativa constitui $\mathrm{O}$ núcleo da reflexão efetivada, expressando a base do republicanismo de Taylor. Nesta representação da democracia, dou destaque ao conceito de bem comum, derivado de sentimentos e ações partilhadas. Nele incide a conexão entre linguagem e cultura, formulada de modo a conferir um valor intrínseco à cultura, e assim sustentar que o que é comum é um bem. Contesto tal formulação, argumentando ser possível rejeitar o relativismo ético sem recurso ao fundamentalismo, caso se aceite a impossibilidade lógica do reconhecimento de uma alteridade radical.

\section{THE CONTEMPORARY MALAISE IN THE PERSPEC- TIVE OF CHARLES TAYLOR}

Isabel de Assis Ribeiro de Oliveira

Keywords: Republicanism; Charles Taylor; Self; Normative order; Common good.

The article presents Taylor's analysis of contemporary malaise, focusing on his critique of the punctual self and political society that follows from it. The presumption that personal identity is only possible through interlocution referred to some normative order constitutes the nucleus of his argument and can be taken as the basis of Taylor's republicanism. In such a representation of democracy, attention is given to the concept of common good which expresses shared feelings and actions. In order to postulate intrinsic worth to any culture so that whatever is common can be said to be good, Taylor establishes a connection between language and culture which is criticized by me. I argue that it is possible to reject relativism without recurrence to fundamentalism, as long as one considers how impossible it is to recognize a radical otherness.

\section{LE MALAISE CONTEMPORAIN SELON LA PERSPECTIVE DE CHARLES TAYLOR}

Mots-clés: Républicanisme; Charles Taylor; Self; Ordre normatif; Bien commun.

L'article présente l'argument de Charles Taylor à propos du malaise contemporain, et est fondé sur sa critique de la conception libérale du sujet et de la société politique qui en découle. La postulation d'une identité personnelle, qui n'existe que grâce à l'interlocution et par rapport à un ordre normatif, est centrale dans la réflexion présentée, et exprime le fondement de son républicanisme. Dans cette représentation de la démocratie, c'est le concept du bien commun qui mérite l'attention. Sa la valeur est issue des sentiments et des actions partagées. C'est sur ce concept que se reflète la connexion existante entre le langage et la culture, formulée de façon à attribuer une valeur intrinsèque à la culture et défendre, ainsi, que ce qui est commun est un bien. Je conteste cette formulation, car je défends qu'il est possible de rejeter le relativisme éthique sans avoir recours au fondamentalisme, à partir du moment où l'on accepte l'impossibilité logique de la reconnaissance de l'altérité radicale. 